\title{
CCC-based muon telescope for examination of natural caves
}

\author{
L. Oláh ${ }^{1}$, G. G. Barnaföldi ${ }^{2}$, G. Hamar ${ }^{2}$, H. G. Melegh ${ }^{3}$, G. Surányi ${ }^{4}$, and D. Varga ${ }^{1}$ \\ ${ }^{1}$ Eötvös Loránd University, 1/A Pázmány P. sétány, 1117 Budapest, Hungary \\ ${ }^{2}$ Institute for Particle and Nuclear Physics, Wigner Research Centre for Physics of the HAS, \\ 29-33 Konkoly-Thege Miklós Str. 1121 Budapest, Hungary \\ ${ }^{3}$ Budapest University of Technology and Economics, 3-9 Múegyetem rkp., 1111 Budapest, Hungary \\ ${ }^{4}$ Geological, Geophysical and Space Science Research Group of the HAS, Eötvös University, 1/C Pázmány P. sétány, \\ 1117 Budapest, Hungary
}

Correspondence to: L. Oláh (laszlo.olah@cern.ch)

Received: 25 July 2012 - Published in Geosci. Instrum. Method. Data Syst. Discuss.: 24 September 2012

Revised: 4 December 2012 - Accepted: 10 December 2012 - Published: 18 December 2012

\begin{abstract}
A portable cosmic muon detector has been developed for geophysical applications: searching for large scale underground rock/soil inhomogeneities and underground cavities. The designed muon telescope called a muon tomograph is based on the recently developed closed cathode chamber (CCC) technology, which provides a cheap, easy handling, portable, and power efficient detector system able to work even in extreme conditions (e.g. high humidity, low/high temperature). The muon telescope has a detection surface of approximately $0.1 \mathrm{~m}^{2}$ with a $10 \mathrm{mrad}$ angular resolution. Tests have been performed in natural caves and artificial tunnel systems as well. In this paper a summary of the first results on tomographic cavities are presented and the geophysical and possible industrial use of the cosmic muon tomographic technology is indicated.
\end{abstract}

\section{Introduction}

Cosmic muons have already been applied for environmental studies, such as measurements of snow depth on mountains (George, 1955), search for hidden chambers in the Kephren Pyramid (Alvarez et al., 1970), and investigation of the inner structure of volcanos (Nagamine et al., 1995; Tanaka et al., 2007; Lesparre et al., 2010). All these applications are based on the energy loss of muons, which implies that the measured flux depends on the traversed material.

During such measurements, detector systems typically developed for high energy physics experiments record the number and direction of the incoming muons. Our portable muon tomograph is similar to those applied in particle physics instrumentations, but it has been specially developed and built for geophysical applications with the main emphasis on power efficiency and portability. These features provide flexible possibility of tomographic mapping of soil density, by measuring the angular distribution of cosmic muons from an observation point below the structures to be investigated.

Hungary and especially Budapest is rich in sedimental rocks, which are mainly limestone, clay and dolomite, providing an excellent possibility to find cavities and caverns over passages by cosmic muon tomography.

Our recent paper introduces the basic structure of the muon tomograph (Barnaföldi et al., 2012) developed by the REGARD group (Eötvös Loránd University and Wigner RCP RMI collaboration for R \& D of gaseous detectors). In Chapter 4 our results on geophysical applications, mapping caverns and tunnels at different places in Hungary are presented:

i. The basic tests were done in the gaseous detector laboratory.

ii. First underground laboratory tests have been performed in the Jánossy pit within the campus of the Wigner RCP of the HAS

iii. Then we moved the detector to the Molnár János Cave, Budapest. Here, the relief of József Hill above the cave was reconstructed.

iv. This was followed by measurements in the Ajándék (Gift) Cave in the Pilis mountains. 


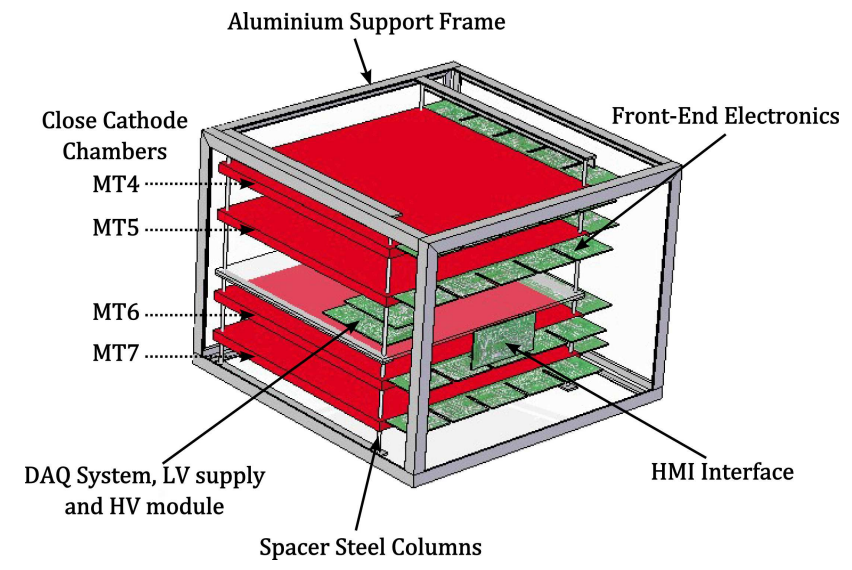

Fig. 1. The layout and structure of the muon tomograph, based on Barnaföldi et al. (2012).

v. Another place where we performed our tests was the purely-mapped artificial cellar system at Kőbánya, Budapest.

All these tests were performed at $\sim 10-70 \mathrm{~m}$ depth in sedimental rocks, duration of the data collecting were in weeklymonthly periods.

\section{Structure of the portable muon tomograph}

The design of the detector aimed at commonly optimizing the sometimes mutually contradicting aspects of effective sensitive surface, angular resolution, detection efficiency, portability (weight, resistance to mechanical shocks), low power consumption and cost efficiency. Cosmic ray detectors should have as large a sensitive area as possible to collect enough statistics during the shortest possible measurement period. However, the interior of natural caves may be difficult to access requiring human handling, which limits size and weight of the detector. We have chosen a specific size which fitted into the Ajándék Cave, Pilis, Hungary, described in Barnaföldi et al. (2012), for a study which was guided by geophysical and speleological interest. It is relatively easy to handle manually: size of the complete system is $51 \times 46 \times 32 \mathrm{~cm}^{3}$, and its total weight is $13 \mathrm{~kg}$.

The muon tomograph consists of four parallel layers of $1 \mathrm{~cm}$ thick CCC chambers developed by the REGARD Group (Varga et al., 2011) and denoted by "MT4", "MT5", "MT6" and "MT7" in Fig. 1. Each detector layer provides two-dimensional position information with projective geometry. The four detector layers, with sensitive surfaces of $32 \mathrm{~cm} \times 32 \mathrm{~cm}$ each, were installed such that the upper and lower pairs are closer to each other $(3.0 \mathrm{~cm})$, and the separation between the two middle units is larger $(16.0 \mathrm{~cm})$.

Our detector system, like the standard MWPC (Multiwire Proportional Chamber) detectors, requires continuous gas flow during data collecting. In our case, the gas is a non-

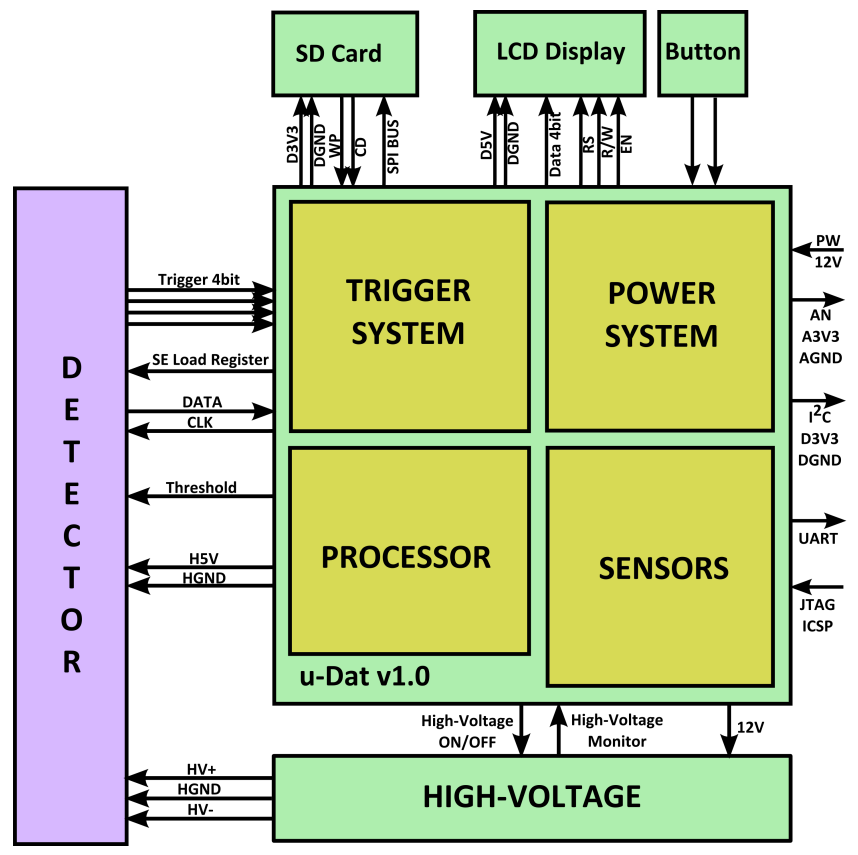

Fig. 2. The schematic plan of the electronics system of the muon tomograph (Barnaföldi et al., 2012).

flammable mixture of $\mathrm{Ar}$ and $\mathrm{CO}_{2}$ in $80: 20$ proportion. A standard 10 liter bottle (with 150 bar filling pressure) is sufficient for 20 days of continuous operation at $\sim 3 \mathrm{~L} \mathrm{~h}^{-1}$ flow. The muon tomograph is contained in a Plexiglas box filled also with the chamber gas, which besides giving mechanical support, provides environmental isolation.

\section{Data acquisition and storage}

The portable detector design requires dedicated electronics to handle all the tasks of the muon tomograph including data management, high-voltage supply and user interface. Therefore, a custom made electronics has been designed in order to optimize the size and the power consumption.

To preserve the total modularity, we decomposed the parts according to their functionality as shown in Figs. 1 and 2. We distinguish three main modules: a processor board (motherboard) which controls the data acquisition including the lowvoltage power system (LV), a high-voltage module (HV) to operate the chambers, and a human-machine interface block (HMI) for maintenance and data storage.

The hearth of the DAQ system is a PIC32 type microcontroller, which is responsible for the read out of the front-end electronics and of the environmental sensors as well as for the data storage. The PIC32 device, whose performance is totally suitable for the tomographic environment, works at $80 \mathrm{MHz}$. The control firmware - which defines the operation of the entire DAQ system - was implemented within a statemachine model. The utilization of such technique enables the 


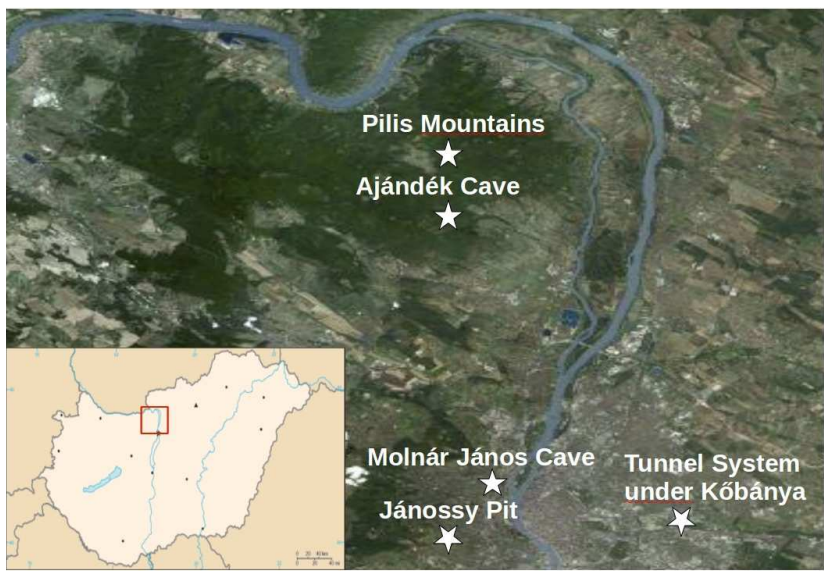

Fig. 3. Test measurements have been taken in Hungary with the REGARD muon tomograph.

software to work robustly and reduces the possibility of errors during the operation.

All the recorded events were written on a standard SD card which is easily accessible to the user via the front panel (HMI). With a portable memory of $2 \mathrm{~GB}$ capacity, the system stored up to 10 million events corresponding to approximately 2 months of measurement time in 10 -meter soil equivalent depth $\left(\rho_{\text {soil }} \approx 2 \mathrm{~g} \mathrm{~cm}^{-3}\right)$. The processor also monitors analog environmental parameters such as humidity or temperature assigned to each event. By using these records, we are able to reconstruct the whole timeline of each measurement and identify errors during the operation.

The high-voltage parts are housed in a separated board with appropriate protection against electric shocks. Two HV lines supply the chambers with typical values of $+1000 \mathrm{~V}$ and $-660 \mathrm{~V}$ which are realized by a divider circuit from the ground independent unit. All analog and digital signals connected to the high-voltage parts are separated by optocouplers and isolation amplifiers.

The low-voltage power supply of the auxiliary electronics, the trigger subsystem and the environmental sensors were placed on the processor board near the PIC32 type microcontroller. The detector is supplied through a single line, nominally at $12 \mathrm{~V} \mathrm{DC}$. The total current consumption of the complete muon tomograph system, including all subunits is $380 \mathrm{~mA}$ which makes it capable of working more than 5 days with a standard 50 Ah battery.

\section{Detector tests in natural and artificial cavern systems}

Detector tests described in Sects. 4.1-4.3 were performed in different places denoted by stars on the relevant map in Fig. 3. To determine the precise geophysical locations for each data collecting, reference maps have been produced, shown on Figs. 4, 7, and 8. The topographical coordinates and contours were generated by SURFER 9.0 program,
Table 1. Environmental conditions and parameters of recorded data.

\begin{tabular}{lrrrrr}
\hline Place & $\begin{array}{r}\text { Depth } \\
{[\mathrm{m} . \text { s. e.] }}\end{array}$ & $\begin{array}{r}\text { Duration } \\
{[\text { days }]}\end{array}$ & $\begin{array}{r}\text { Events } \\
{\left[10^{6}\right]}\end{array}$ & $\begin{array}{r}\text { Temp. } \\
{\left[{ }^{\circ} \mathrm{C}\right]}\end{array}$ & $\begin{array}{r}\text { Humid. } \\
{[\%]}\end{array}$ \\
\hline Lab & 0,2 & $>100$ & $>50$ & $27 / 26$ & $32 / 40$ \\
Jánossy & 13,35 & 22 & 3 & $15 / 13$ & $60 / 90$ \\
Molnár J. & $30-80$ & 45 & 0.5 & $26 / 26$ & $60 / 100$ \\
Ajándék & 60 & 50 & 0.17 & $13 / 11$ & $50 / 100$ \\
Pilis & $0,2,5$ & 0.5 & 0.5 & $10 / 8$ & $60 / 100$ \\
Kóbánya & 20 & 40 & 0.5 & $13 / 11$ & $50 / 100$ \\
\hline
\end{tabular}

based on high-precision geodesical TOPCON GPS data up to $3-5 \mathrm{~cm}$ accuracy. The uncertainties of the calculated contours is about $\pm 0.8 \mathrm{~m}$. Further parameters and conditions of the data collecting such as duration, depth in meter soil equivalent (m.s.e.), recorded number of events, in/out temperature, and in/out humidity are summarized in Table 1 . The large range of measured environmental conditions show the detector is well suited to field operations.

\subsection{Relief reconstruction above the Molnár János Cave}

Before the geophysical measurements, basic performance tests were done at the REGARD laboratory. First underground tests were performed in the Jánossy pit, which is a $30 \mathrm{~m}$ deep tunnel system at the campus of the Wigner RCP of the HAS, Budapest, Hungary located on a hill in the Buda Mountains. Due to lack of ventilation in the Jánossy pit it was possible to test and optimize the environmental isolation concept in highly humid air. Following these successful tests the next step was to perform relief reconstruction in a (well accessible) natural cave.

The Molnár János Cave is located under József Hill in the Buda Hills in the 2nd district of Budapest. Including all the recently discovered parts, the total length of the cave-system is about $8000 \mathrm{~m}$ of which $95 \%$ is underwater cavern. The dry part of the cave starts with an artificial $200 \mathrm{~m}$ tunnel leading to the so called $\mathrm{CO}_{2}$ chamber with a lake inside. The water-system of the cave is fed by both thermal and karst springs (Surányi et al., 2010).

In this cave the tunnel (near the lake's chamber) provides a test area with $\sim 100 \%$ humidity and $\sim 26^{\circ} \mathrm{C}$ stable temperature, thanks to the deep underwater thermal sources under the dry caverns. During the test we used the first version of the REGARD muon tomograph which was a similar CCCbased detector as described in Sect. 2, but with a smaller active area $12.8 \times 19.2 \mathrm{~cm}^{2}$. The total duration of the measurements in the Molnár János Cave was 3 times 2 weeks at different points of the artificial tunnel. The collected data were only $20 \mathrm{k}$ events at $\sim 70 \mathrm{~m}$ under the surface, while under the slope, we took $180 \mathrm{k}$ events $(\sim 30 \mathrm{~m})$. This latter measurement with the highest statistics was used for the data analysis below. 


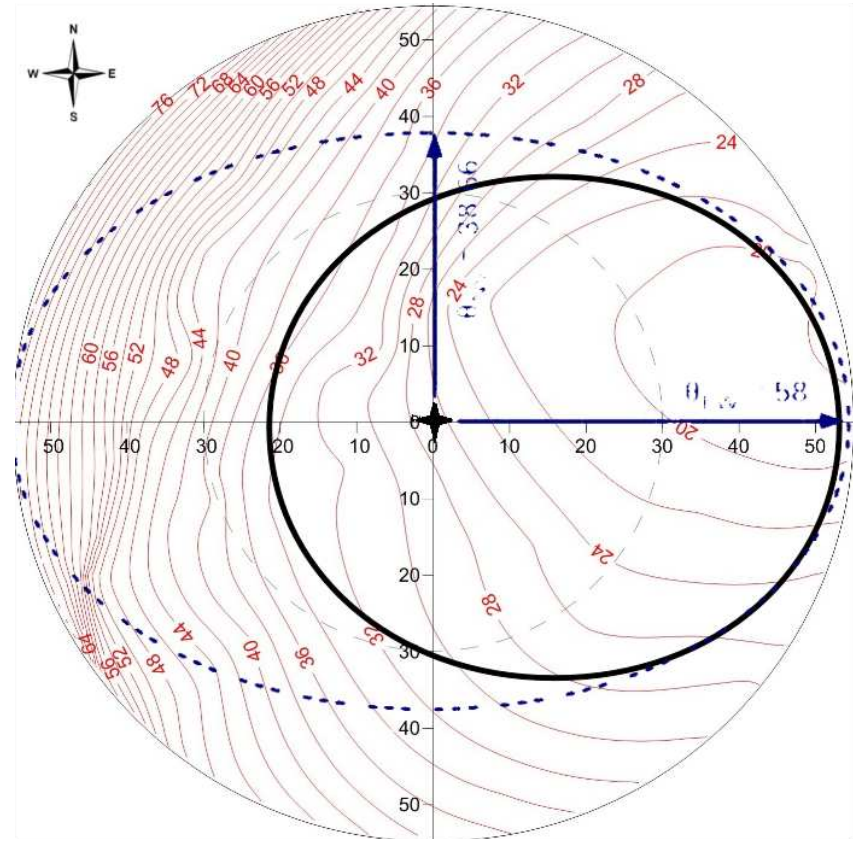

Fig. 4. The local map and the projection of the view angle of the József Mountain above the Molnár János Cave. The detector was placed at the origo within the west-east orientational artificial cavern. Dashed blue lines are for the whole view angle of the muon tomograph, while solid black lines shows the region useable for the relief reconstruction. Red contours show the thickness of the material in meter soil equivalent (m. s. e.).

The local map and the projection of the view angle of the József Mountain above the Molnár János Cave is plotted on Fig. 4. The detector was placed at the origin (star) of the coordinate system, while a dashed blue line shows the whole view angle of the muon tomograph. Relief reconstruction, shown in Fig. 5, has been performed in the region where the statistical fluctuations are below $3 \%$ (highlighted by solid black lines on Fig 4). The artificial tunnel goes along the west-east directional axis. The thickness of the soil to the zenith/azimuth directions was calculated based on GPS data and a polygon model, visualized as contours with numbers on Fig. 4.

The reconstructed surface based on the measured muon flux has been plotted on Fig. 5. Here we cut the view angle in order to use bins with high statistics only, plotted as solid black lines on Fig. 4. The reconstruction based on simple assumptions for $\sim 10-30 \mathrm{~m}$ material length: exponential decrease of the muon flux with the depth with $\rho \approx 2 \mathrm{~g} \mathrm{~cm}^{-3}$. The obtained results are in good agreement with comparison to the inner solid contours on Fig. 4.

\subsection{Measurements in the Ajándék Cave}

The Ajándék (Gift) Cave is expected to be connected to the Ariadne Cave System in the Pilis mountains - a member of the Transdanubian Mountain Range, Hungary. The Pilis

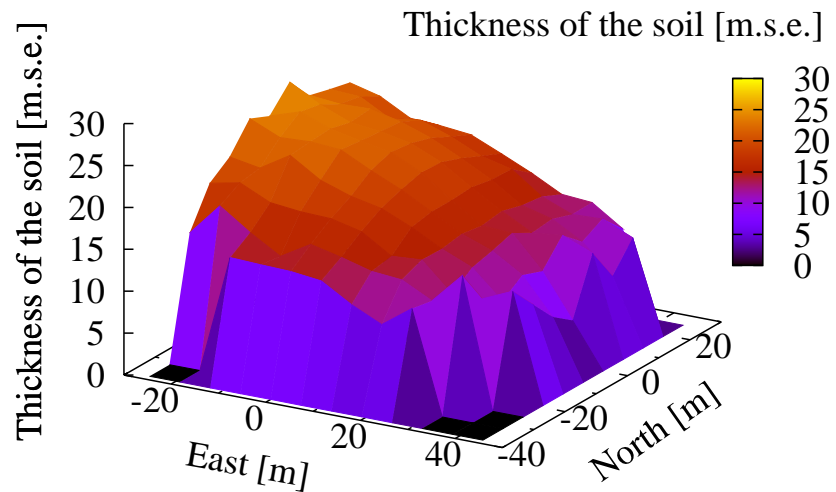

Fig. 5. The soil thickness above the Molnár János Cave, is given in meter soil equivalent (m. s. e.).

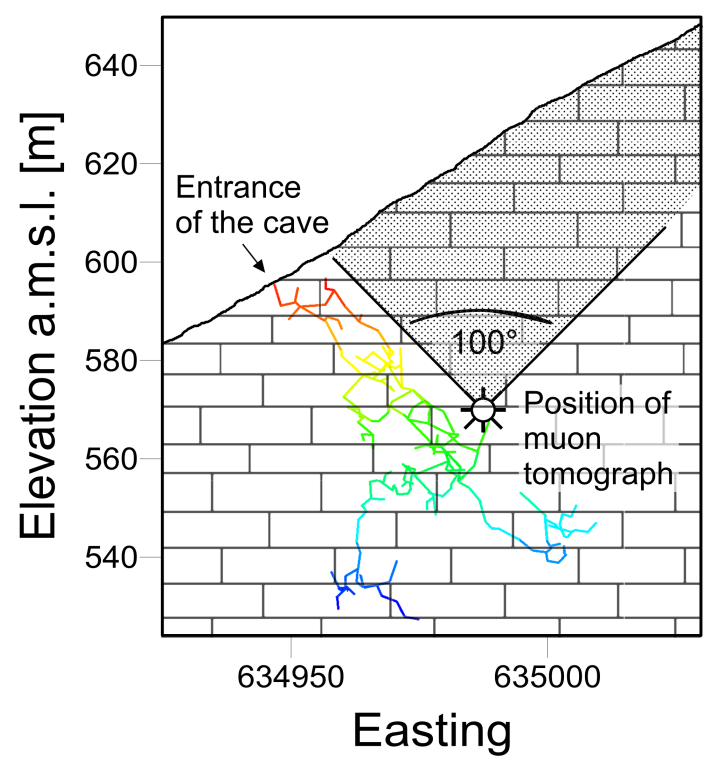

Fig. 6. The west-east cross section of the Ajándék Cave (Barnaföldi et al., 2012).

mountain consists of well karstified upper triassic limestone. Our objective, the Ajándék Cave is located under the steep slope of the Pilis Mountain. There are several other caves in this region of the mountain producing dense, multilevel cavern network with the total length of about $15000 \mathrm{~m}$. The Ajándék Cave is the uppermost known member of the system discovered by the Ariadne Karst and Speleology Association in 1998. Today the cavern is about $1000 \mathrm{~m}$ long. The schematic view of the west-east cross section of the Ajándék Cave is plotted in Fig. 6 with color coding corresponding to the depth of the caverns. The view angle of the detector is highlighted as shaded area on the plot.

The angular distribution of the cosmic muon flux has been measured during 50 days. Totally, $170 \mathrm{k}$ events with well identified muon tracks have been collected at the average frequency of $0.04 \mathrm{~Hz}$. 


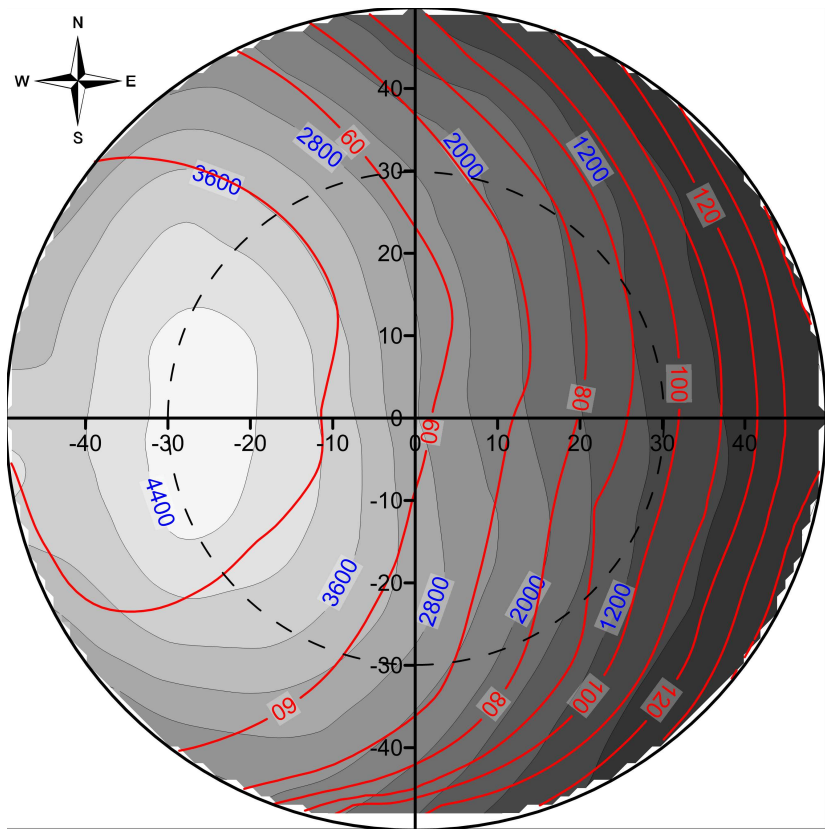

Fig. 7. Muon flux black contours in $\mathrm{sr}^{-1} \mathrm{day}^{-1}$ units compared to the GPS-based direct measurements of the rock/soil thickness above the deployment point in the Ajándék Cave (Barnaföldi et al., 2012).

The angular distribution was compared to rock thickness in Fig. 7. Here, red contours represent the thickness of the rock/soil above the detector deployment point (called "Cinema Chamber") at given angles. Calculations of the contours required topographical GPS coordinates based on our measurements and in addition precise polygon measurement of the muon tomograph's position within the cave. The shortest distance to the surface was about $50 \mathrm{~m}$ in the direction of $25^{\circ} \pm 5^{\circ}$ to the West and $0^{\circ} \pm 15^{\circ}$ to North and South. Comparing this to the muon flux measurement drawn by topographic grayscale divided by the known angular distribution on the surface (Bogdanova et al., 2006; Jeng-Wei Lin et al., 2010; Bugaev et al., 1998), the flock of contours and grayscale shows strong correlation. Based on the similarity of the contours, at this stage one can conclude that no underground structure above the observation point is clearly identifiable (a cavern would correspond to a local flux increase).

\subsection{Measurements at Kőbánya}

Our latest measurements were done at a sedimental area of Pest Plain (East Budapest) in Hungary, called Kőbánya (Stone quarry). This area is now part of the city of Budapest, however at the end of the 19th century this place was one of the main stone quarries around the city. Because of the difficulty of removing the uppermost several meter thick sediment layer, the late Miocene limestone was taken out from underground mines forming huge artificial cavern system with about $300 \mathrm{~km}$ length. Part of this cavern-system is filled up with groundwater, but the upper ducts are acces-

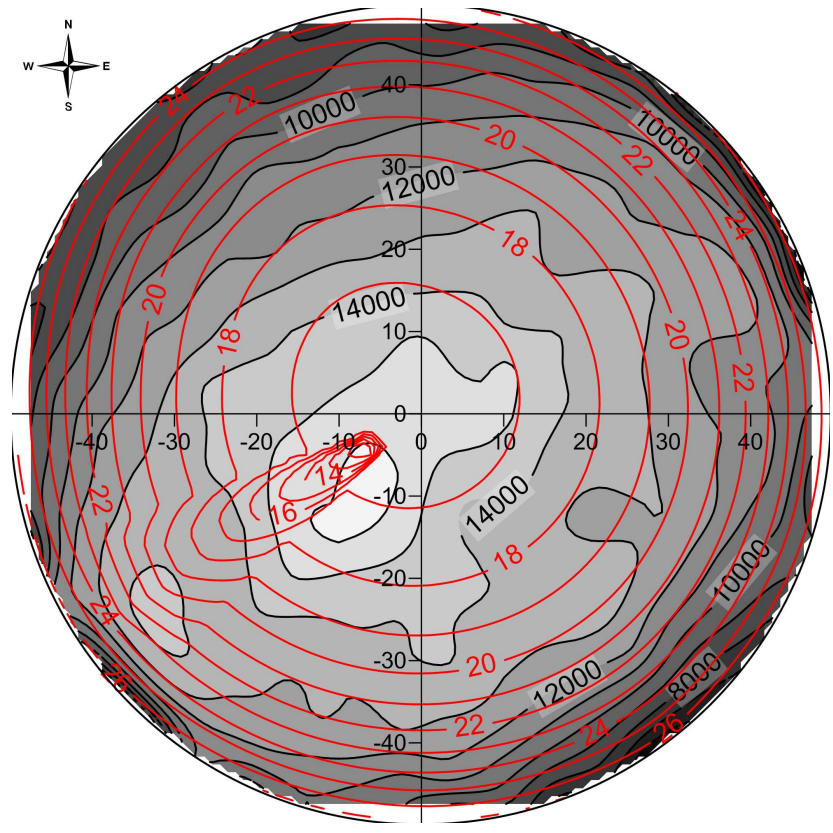

Fig. 8. The muon tomograph at Kőbánya, 2 meters away from the axis of a blowhole. Solid red lines show the integrated lengths in the given direction, while the shading shows the measured muon flux in $\mathrm{sr}^{-1}$ day $^{-1}$ units.

sible. These dry-caverns are used for vine and bier cellars equipped with air flow systems with artificial vertical shafts.

The main aim of these measurements at the caverns of Kóbánya was to test the applicability of the REGARD muon tomograph for a possible industrial use. The presence of such an unknown, crashed, and unaccessible underground structure within the urban area represents a potential threat. Washouts can happen after heavy rainfalls or in case of buildingup empty areas during future urban planning or recultivation. Cosmic muon tomography might be a good method to measure hidden or forgotten caverns or ducts, instead of usual application of geophysical measurements in noisy, urban areas.

The in use artificial tunnels under Kőbánya at some places are equipped with air-flow systems, which are vertical (zenith) shafts of about $1 \mathrm{~m}$ diameter and $\sim 10-20 \mathrm{~m}$ in length for the purpose of obtaining the ventilation for the underground system. Some of these blowholes are partially filled or foundered. We chose working blowholes for the target of our measurements, which are open to the sky at the zenith. With these known holes the large scale soil inhomogeneities can be tested, however we note that the local environment of the blowholes might still contain unknown nonhomogeneous rock structures.

Several measurements were performed in a cavern of the Kóbánya, at 17 meter soil equivalent depth. For the blowhole study we have placed the detector $\sim 2.5 \mathrm{~m}$ away from the axis of a vertical shaft, headed to the zenith. 
In Fig. 8 we plotted the results of two measurements: solid red lines stand for the calculated thickness of the soil/rock at given zenith/azimuth direction based on our local GPS measurements on the surface and polygon method under the ground; topographical lines connect to equal thickness points. In parallel, we plotted the muon flux at given directions by topographical shading. Both were generated by SURFER 9.0 program and include the necessary geometrical corrections. The correlation of density-length and muon flux can be seen for both the homogeneous soil and for the hole as well even for these low statistics.

\section{Summary and conclusions}

Our CCC-based portable muon tomograph is designed for outdoor use thanks to its special feature of compactness and low power consumption. We have shown that the detector is capable of realizing meaningful muon tomography measurements. Several underground tests have been performed in artificial and natural caves as well as up to the -70 meters level. For all cases the GPS based surface measurements and our muon flux measurements were in fair correlations. These results highlight that not only the cosmic muon tomography is an excellent new tool for searching for underground cavities, but that our muon tomograph is a good candidate for these measurements.

Acknowledgements. Authors acknowledge to the REGARD group (Eötvös Loránd University and Wigner RCP of the HAS collaboration for R \& D of gaseous detectors). This work was supported by Hungarian OTKA grants NK778816, NK106119, H07-C 74164, and K10426, the OTKA-KTIA grants 77719, 77815, NIH TET_101_2011-0061 and ZA-15/2009, and Eötvös University. Authors (GGB,DV) also thank the János Bolyai Research Scholarship of the HAS.

Edited by: C. Carloganu

\section{References}

Alvarez L. W., Anderson J. A., Bedwei F. E., Burkhard J., Fakhry A., Girgis A., Goneid A., Hassan F., Iverson D., Lynch G., Miligy Z., Moussa A. H., Sharkawi M., and Yazolino L.: Search for Hidden Chambers in the Pyramids, Science, 167, 832-839, 1970.

Barnaföldi G. G., HamarG., Melegh H. G., Oláh L., Surányi G., and Varga D.: Portable Cosmic Muon Telescope for Environmental Applications, Nucl. Instrum. Meth., A689, 60-69, http://dx.doi.org/10.1016/j.nima.2012.06.015, 2012.

Bogdanova L. N., Gavrilov M. G., $\quad$ Kornoukhov V. N., and Starostin A.S.: Cosmic Muon Flux at Shallow Depths Underground, Phys. Atom. Nucl., 69, 1293, doi:10.1134/S1063778806080047, 2006.

Bugaev E. V., Misaki A., Naumov V. A., Sinegovskaya T. S., Sinegovsky S.I., and Takahashi N.: Atmospheric muon flux at sea level, underground, and underwater, Phys. Rev., D58, 054001, doi:10.1103/PhysRevD.58.054001, 1998.

George E. P.: Cosmic Rays Measure Overburden of Tunnel, Commonwealth Engineer, 1 July, 455-457, 1955.

Jeng-Wei L., Yen-Fu C., Rong-Jiun S., and Shiang-Huei J.: Measurements of angular distribution of cosmicray muon rate, Nucl. Instrum. Meth., A619, 24-27, http://dx.doi.org/10.1016/j.nima.2009.12.017, 2010.

Lesparre N., Gibert D., Marteau J., Déclais Y., Carbone D., and GalichetE.: Geophysical muon imaging: feasibility and limits, Geophys. J. Int., 183, 1348-1361, 2010.

Nagamine K., Iwasaki M., Shimomura K., and Ishida K.: Method of probing inner structure of geophysical substance with the horizontal cosmic ray muons and possible application to volcanic eruption prediction, Nucl. Instrum. Meth., A356, 585-595, 1995.

Surányi G., Dombrádi E., and Leél-össy Sz.: Contribution of Geophysical Techniques to the Exploration of the Molnár János cave (Budapest, Hungary), Acta Carsologica, 39/3, 2010.

Tanaka H., Nakano T., Takahashi S., Yoshida J., Takeo M., Oikawa J., Ohminato T., Aoki Y., Koyama E., Tsuji H., and Niwa K.: High resolution imaging in the inhomogeneous crust with cosmic-ray muon radiography: The density structure below the volcanic crater floor of Mt. Asama, Japan, Earth Planet. Sci. Lett., 263, 104-113, 2007.

Varga D., Hamar G., and Kiss G.: Asymmetric multi-wire proportional chamber with reduced requirements to mechanical precision, Nucl. Instrum. Meth., A648, 163-167, 2011. 